\title{
INDICADORES AGROECONÔMICOS NA AVALIAÇÃO DO CONSÓRCIO ALGODÃO HERBÁCEO + AMENDOIM
}

\author{
Agroeconomic indicators on the evaluation of cotton + peanut intercropping
}

\author{
Afrânio César de Araújo ${ }^{1}$, Napoleão Esberard de Macêdo Beltrão², Martival dos Santos Morais ${ }^{3}$, \\ Jussiara de Lima Oliveira Araújo ${ }^{4}$, Jorge Luiz Xavier Lins Cunha ${ }^{5}$, Stênio Lopes Paixão ${ }^{5}$
}

\begin{abstract}
RESUMO
Objetivou-se estudar a influência de cultivares de algodão e amendoim e épocas relativas de semeadura em consórcio, verificando-se as relações de competitividade entre as duas culturas. O experimento foi conduzido no município de Missão Velha, CE, Brasil, no campo experimental da Embrapa Algodão, no ano agrícola de 2002. Foram analisados 20 tratamentos com 4 repetições, em delineamento estatístico de blocos ao acaso, em esquema de análise fatorial $2 \times 2 \times 4+2+2$, cujos fatores foram duas cultivares de algodão (BRS 186 - precoce 3 e BRS 201), duas cultivares de amendoim (L7 e BR-1), quatro épocas de semeadura (0; 7; 14 e 21 dias) mais as testemunhas isoladas das duas cultivares de algodoeiro e amendoim.Considerando os resultados obtidos para renda bruta, renda líquida e taxa de retorno, considerou-se que não houve vantagem econômica para o produtor quando o algodão foi semeado em consórcio com o amendoim, já que os valores referentes ao consórcio foram menores do que os cultivos isolados.
\end{abstract}

Termos para indexação: Indicadores econômicos, competição, UET.

\section{ABSTRACT}

One aimed with this work to study the influence of cotton and peanut cultivars and relative planting times as intercropping, being verified the relationships of competitiveness among the two cultures. The experiment was carried out in Missão Velha, Ceará State, Brazil, at Cotton Experimental Field of Embrapa in the agricultural year of 2002. Twenty treatments were tested with 4 repetitions, in a randomized block with $2 \times 2 \times 4+2+2$ factorial, the factors being two cultivars of cotton (BRS 186 - precocious 3 and BRS 201), two cultivars of peanut (L7 and BR-1), four planting times (0; 7; 14 and 21 days) plus the isolated controls of the two cultivars of cotton and peanut crops. Considering the results obtained for rude income, surrender liquid and rates of return, one considered that there was not economical advantage for the producer when the cotton was planted in intercrop with the peanut, since the referring values to the intercrop were smaller than the isolated cultivations.

Index terms: Economical pointers, competition, LER.

(Recebido em 23 de março de 2007 e aprovado em 2 de janeiro de 2008)

\section{INTRODUÇÃO}

A prática de consórcios, em especial, de oleaginosas com culturas alimentares como cereais e leguminosas vem sendo utilizada pelo pequeno produtor como maneira de solucionar problemas relacionados às irregularidades climáticas no semi-árido (BELTRÃO et al., 1984). Por apresentarem maior diversidade cultural, os agrossistemas consorciados podem representar, de certa forma, um "retorno" ao ambiente natural, tendo portanto, maior estabilidade. Consórcios são também bastante utilizados de modo a beneficiar tanto a dieta quanto a receita econômica do produtor, que fica menos sujeito a perdas totais da produção devido a estresse hídrico, ataque de pragas ou prejuízos decorrentes da oscilação de preço no mercado.

Os principais inconvenientes dos consórcios são as dificuldades na utilização de tecnologia de alto nível, principalmente operações mecanizadas relacionadas à capinas, aplicação de inseticidas, fungicidas, herbicidas, adubação e irrigação, além de sombreamento e esgotamento de solo, por conta da intensa utilização da área (PORTES, 1996).

Em função do seu valor nutricional e das variadas formas de consumo, o amendoim (Arachis hypogaea L.) é uma oleaginosa bastante cultivada no Brasil. O seu alto

\footnotetext{
'Biólogo, Mestre - Centro de Ciências Agrárias/CECA - Departamento de Fitossanidade - Universidade Federal de Alagoas/UFAL - Br 104 , Km 85 Campos Delza Gitai - 57100-000 - Rio Largo, AL - afraniobiologo@hotmail.com

²Engenheiro Agrônomo, Doutor - Departamento de Manejo Cultural/MC - Embrapa Algodão - Rua Osvaldo Cruz, 1143 - Centenário - Cx. P. 174 - 58107720 - Campina Grande, PB - napoleao@cnpa.embrapa.br

${ }^{3}$ Biólogo, Mestre - Departamento de Biologia/DB - Universidade Aberta Vida/UNAVIDA - Rodovia Br 230, s/n - 58037-000 - João Pessoa, PB martivalcg@bol.com.br

${ }^{4}$ Graduanda em Biologia - Centro de Ciências Biológicas e da Saúde/CCMS - Departamento de Biologia - Universidade Estadual da Paraíba/UEPB Avenida das Baraúnas, 351 - Campus Universitário Bodocongó - 58109-753 - Campina Grande, PB - jussiaralima@hotmail.com

${ }^{5}$ Engenheiros Agrônomos, Mestrandos em Agronomia - Centro de Ciências Agrárias/CECA - Departamento de Fitossanidade - Universidade Federal de Alagoas/UFAL - Br 104, Km 85 - Campos Delza Gitai - 57100-000 - Rio Largo, AL - jlxlcunha@yahoo.com.br; stenio_lopes@ig.com.br
} 
poder de adaptação às mais variadas condições contribui também para a sua grande distribuição no País. Na Paraíba, embora essa não seja uma cultura tradicional, o ciclo curto e a fácil comercialização que essa leguminosa apresenta impulsionam o seu cultivo. Embora já tenha sido utilizado como alimento animal, o amendoim é hoje uma importante fonte nutritiva, em vários países em desenvolvimento (SILVA \& BELTRÃO, 1998).

Tanto o algodão quanto o amendoim já são cultivados em consórcio com várias culturas. No entanto, a literatura envolvendo a associação entre estes dois vegetais é praticamente inexistente no Brasil. O algodão (Gossypium hirsutum L. r) é bastante resistente à seca embora seja exigente em sais minerais. $\mathrm{O}$ amendoim, por sua vez, além de ser uma importante fonte nutritiva para o homem, sendo uma leguminosa, estabelece uma relação simbiótica com bactérias fixadoras de nitrogênio. $\mathrm{O}$ consórcio entre esses dois vegetais merece ser melhor estudado já que há a possibilidade de uma produção satisfatória para ambas as culturas, quando associadas.

Nos últimos anos foram realizados alguns trabalhos envolvendo a consorciação entre algodão e a também oleaginosa gergelim (Sesamum indicum L.). Beltrão et al. (2001a,b) estudaram o comportamento dos fatores cultivares e configurações de plantio, em quatro épocas relativas de plantio $(0 ; 7 ; 14 ; 21$ dias $)$, no consórcio gergelim $\mathrm{x}$ algodão.

A avaliação dos agrossistemas consorciados deve envolver indicadores econômicos e agroeconômicos, tais como: índice de uso eficiente da terra (UET), índice de agressividade, coeficiente relativo populacional, vantagem monetária e renda líquida, que parece ser a variável econômica mais indicada para a avaliação de consórcios comparando-os ao monocultivo. Se bem equilibrados e definidos, principalmente em relação à cultivares, configurações de plantio e arranjo de plantas, os sistemas consorciados apresentam quase sempre vantagem monetária (BELTRÃO, 2001a).

Objetivou-se, com este trabalho, avaliar a influência de cultivares de algodão e amendoim e épocas relativas de semeadura em consórcio, a partir de indicadores agroeconômicos que podem ser utilizados em confrontações de agroecossistemas consorciados e solteiros, visando a eleição dos sistemas mais vantajosos.

\section{MATERIALE MÉTODOS}

O experimento foi conduzido em condições de sequeiro, no Campo Experimental da EMBRAPA da cidade de Missão Velha, CE, região do Cariri, a 7 42’07" de latitude e 39 24' 18" de longitude, altitude de 360 m. A precipitação pluviométrica total, no período de condução do experimento (fevereiro a julho) foi de 490,6 $\mathrm{mm}$. O delineamento experimental foi o de blocos ao acaso, com 4 repetições envolvendo 20 tratamentos em esquema de análise fatorial $2 \times 2 \times 4+2+2$, cujos fatores foram: duas cultivares de algodão, duas cultivares de amendoim em quatro épocas de semeadura, sendo a leguminosa plantada ao mesmo tempo, 7, 14 e 21 dias após a malvácea, mais as culturas isoladas. $\mathrm{O}$ espaçamento no monocultivo foi de $1,0 \times 0,2 \mathrm{~m}$ para o algodão e $0,5 \times 0,2 \mathrm{~m}$ para o amendoim. No consórcio, o amendoim foi semeado entre as fileiras do algodão, à uma distância de $0,5 \mathrm{~m}$, em relação à malvácea. Utilizaram-se as cultivares BRS 186-Precoce 3 e a BRS 201 para o algodão e as L7 e BR-1, para o amendoim. A adubação NPK foi realizada nas quantidades: $10 \mathrm{~kg} \mathrm{ha}^{-1} \mathrm{de} \mathrm{N}, 80 \mathrm{~kg}$ ha $^{-1}$ de $\mathrm{P}_{2} \mathrm{O}_{5}$ e $60 \mathrm{~kg} \mathrm{ha}^{-1}$ de $\mathrm{K}_{2} \mathrm{O}$, apresentando como fontes sulfato de amônio, superfosfato triplo e cloreto de potássio, respectivamente, aplicados em função das exigências nutricionais segundo recomendações de Mendes (1965). O solo do local é de textura arenosa e classificado como Neossolo Regolítico (EMBRAPA, 1999).

Foram analisadas as seguintes variáveis: índice de uso eficiente da terra (UET), que corresponde à área relativa da terra, sob condições de plantio isolado, e é utilizada para delinear os rendimentos alcançados no consórcio; índice de agressividade, que refere-se primordialmente às relações de competitividade (quando seu valor é zero, tem-se o indicativo de que as duas espécies serão iguais em relação à força de competição, quando seu valor é diferente de zero, as forças de competição são diferentes, sendo que a de sinal positivo predomina em relação a de sinal negativo); coeficiente relativo populacional, que relaciona-se com as relações competitivas interespecíficas em um consórcio; renda bruta, que corresponde ao valor total da produção das duas culturas envolvidas, sem considerar os custos; renda líquida, que corresponde ao valor total líquido da produção das duas culturas envolvidas; e taxa de retorno, que corresponde à relação entre a renda bruta e o total dos custos da produção.

Após a efetivação da análise de variância (ANOVA), os dados obtidos foram submetidos ao teste de Tukey e regressão através de polinômios ortogonais (regressão polinomial), segundo recomendações de Gomes (1985).

\section{RESULTADOS E DISCUSSÃO}

Com relação ao UET houve significância apenas para o fator épocas relativas de semeadura $(\mathrm{P} \leq 0,01)$ e 
interações entre os fatores cultivares de amendoim $\mathrm{x}$ épocas relativas de semeadura $(\mathrm{P} \leq 0,01)$ e cultivares de algodão $\mathrm{x}$ cultivares de amendoim $(\mathrm{P} \leq 0,05)$. $\mathrm{O}$ efeito da interação tripla entre os três fatores trabalhados não foi significativo para nenhuma das variáveis analisadas neste trabalho.

Quanto ao fator épocas relativas de semeadura, aos 7, 14 e 21 dias de semeadura do amendoim, após a semeadura do algodão, o sistema consorciado proporcionou UET abaixo de 1,00, o que implica dizer que o consórcio algodoeiro herbáceo + amendoim só proporciona vantagem biológica em relação ao monocultivo quando a leguminosa é semeada ao mesmo tempo que a malvácea (Figura 1). Mesmo assim a superioridade do consórcio foi de apenas $7 \%$, muito pequena em função da redução da produtividade do amendoim. Além do mais, a simples avaliação de agrossistemas consorciados a partir do UET não é muito confiável, pois ele fornece apenas a dimensão física do sistema (BELTRÃO, 1984).

No que toca ao efeito da interação significativa entre os fatores cultivares de algodão e cultivares de amendoim para o UET, verificou-se que, quando o consórcio envolve as cultivares BRS 201 de algodão e L7 de amendoim o índice de uso eficiente da terra se eleva. Mesmo assim, o valor ficou abaixo de 1,00, o que evidencia a desvantagem do sistema consorciado em relação ao monocultivo (Tabela 1).

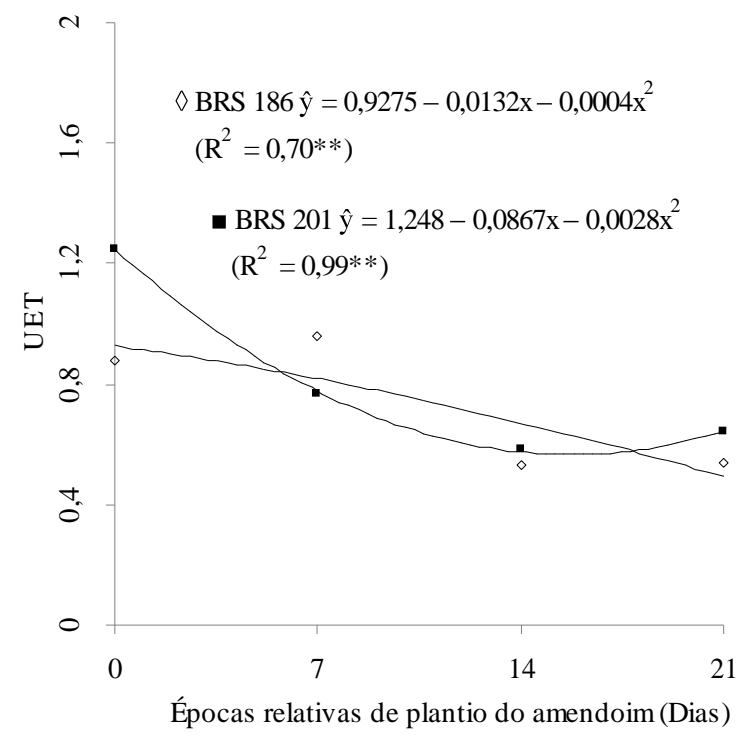

Figura 1 - Regressão do índice de uso eficiente de terra (UET) em função das épocas relativas de semeadura do amendoim. Épocas relativas de semeadura/algodão.
Tabela 1 - Desdobramento da interação significativa entre os fatores cultivares de algodão e cultivares de amendoim, para a variável uso eficiente da terra (UET).

\begin{tabular}{ccc}
\hline Cultivares de e algodão & \multicolumn{2}{c}{ UET } \\
& L7 & BR -1 \\
\hline BRS 186 & $0,67 \mathrm{aA}$ & $0,79 \mathrm{aA}$ \\
BRS 201 & $0,85 \mathrm{bA}$ & $0,77 \mathrm{aA}$ \\
\hline
\end{tabular}

Médias assinaladas pela mesma letra maiúscula nas linhas e por mesma letra minúscula nas colunas não diferem entre si pelo teste de Tukey, a 5\% de probabilidade.

Quanto à variável índice de agressividade apenas o fator épocas relativas de semeadura foi significativo, a $1 \%$ de probabilidade. $\mathrm{O}$ algodoeiro foi sempre mais agressivo que o amendoim.

As épocas relativas de semeadura da leguminosa constituíram elemento de fundamental importância para a avaliação do sistema, pois o índice de agressividade aumentou de modo contínuo em função das épocas de semeadura. Quando o amendoim foi semeado no mesmo dia que o algodoeiro, o valor médio para essa variável foi 0,23 . Já quando semeada 21 dias após a malvácea, a leguminosa sofreu forte competição, elevando-se o índice para 0,59 (Figura 2). Percebe-se que, na medida em que se distanciou a semeadura do amendoim, a intensidade da competição imposta pelo algodoeiro foi gradualmente elevada, o que acabou por suprimir qualquer reação por parte da leguminosa, principalmente nas duas últimas épocas de semeadura (14 e 21 dias).

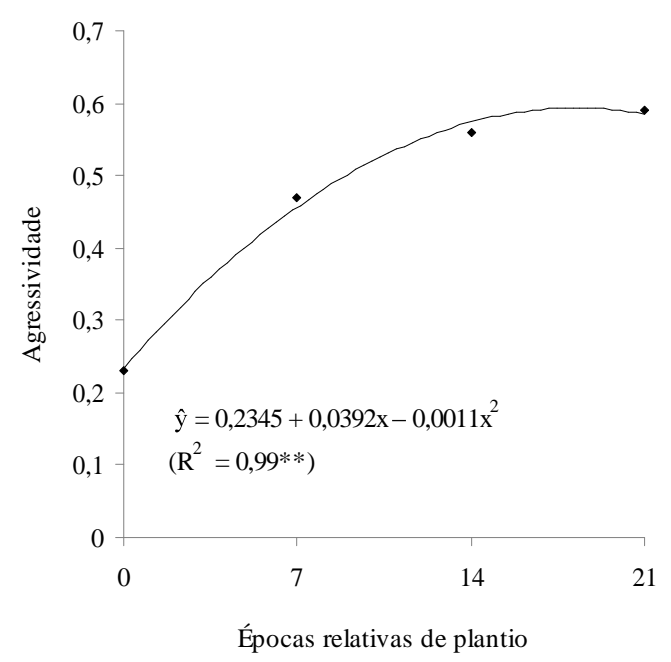

Figura 2 - Regressão do índice de agressividade, em função das épocas relativas de semeadura. 
A competição por fatores de crescimento (água, nutrientes e luz) afeta o rendimento das culturas consortes, sendo a luz um dos principais, senão o principal fator limitante e que constitui importante empecilho à utilização de consórcios (PORTES, 1996; TRENBATH, 1979). A menor disponibilidade de energia luminosa, por conta do sombreamento muitas vezes verificado em consórcios provoca diminuição da taxa fotossíntética. Em conseqüência, os fatores de produção, de modo geral, são afetados.

Com relação ao coeficiente relativo populacional (K), apenas para o índice Kam (amendoim) houve efeito significativo para os fatores cultivares de amendoim $((\mathrm{P} \leq 0,01)$ e épocas relativas de semeadura $(\mathrm{P} \leq 0,01)$, bem como para a interação entre esses fatores $(\mathrm{P} \leq 0,01)$ (Tabela 2$)$.

Tabela 2 - Médias dos tratamentos considerando-se a variável coeficiente relativo populacional para o algodão (Kalg.) e para o amendoim (Kam.).

\begin{tabular}{cll}
\hline Fatores & Kalg. & Kam. \\
\hline $\begin{array}{c}\text { Cultivares de } \\
\text { amendoim }\end{array}$ & & \\
L7 & $3,14 \mathrm{a}$ & $0,16 \mathrm{~b}$ \\
BR 1 & $3,07 \mathrm{a}$ & $0,32 \mathrm{a}$ \\
Média & 3,12 & 0,22 \\
\hline
\end{tabular}

Médias seguidas de mesma letra em cada coluna e para cada fator não diferem estatisticamente entre si pelo teste de Tukey, a $5 \%$ de probabilidade.

Este indicador relaciona-se com as relações competitivas interespecíficas em um consórcio. Se uma espécie apresenta um coeficiente relativo populacional menor, igual ou maior que a unidade, significa dizer que ela produz menos, igual ou mais que a produção esperada.

Avaliando-se a variável coeficiente relativo populacional de forma isolada, pode-se concluir que a cultivar BR - 1 é mais resistente à competição interespecífica (Kam. de 0,32), comparando-a com a L7 (Kam de 0,16).

$\mathrm{Na}$ figura 3, observa-se uma queda progressiva significativa do índice Kam. ao longo das épocas de plantio do amendoim, o que culminou com Kam. igual a 0,0, nas duas últimas épocas (14 e 21 dias após a semeadura do algodão).

Quanto à renda bruta, houve efeito significativo apenas para o fator cultivares de algodão $(\mathrm{P} \leq 0,01)$, para a interação significativa entre os fatores cultivares de algodão e cultivares de amendoim $(\mathrm{P} \leq 0,05)$, e para os contrastes monocultivo vs consórcio, para as duas cultivares de algodão e amendoim $(\mathrm{P} \leq 0,05)$, conforme análise de variância.

Analisando-se a tabela 3, verifica-se que a cultivar BRS 201, de algodão quando consorciada com a cultivar L7 de amendoim possibilitou maior renda bruta: $\mathrm{R} \$ 3.614,46$, com o $\mathrm{kg}$ de algodão sendo cotado a $\mathrm{R} \$ 1,30$ e o $\mathrm{kg}$ de amendoim sendo cotado a $\mathrm{R} \$ 1,50$.

Comparando as testemunhas de algodão e amendoim com o cultivo consorciado observa-se que as duas cultivares de amendoim, em cultivo solteiro foram responsáveis por uma renda bruta bem inferior ao consórcio, sendo que a cultivar L7 foi a que apresentou menor valor (Tabela 4).

A renda bruta do algodão solteiro (independentemente da cultivar) foi bem maior comparada com a proporcionada pelo consórcio. Nesse caso, a redução da renda bruta chegou até $60 \%$. Por outro lado, em trabalho no qual algodoeiro herbáceo foi consorciado com sorgo Beltrão et al. (1986b) verificaram que o monocultivo de algodão proporcionou renda bruta maior que o sistema consorciado. No consórcio algodoeiro herbáceo + feijão caupi pitiúba Beltrão et al. (1986a) observaram resultados semelhantes, ou seja, a renda bruta do sistema consorciado foi menor que a do algodão solteiro.

Com relação à renda líquida, houve efeito significativo apenas para o fator cultivares de algodão $(\mathrm{P} \leq$ $0,05)$ e para os contrastes entre os monocultivos duas cultivares de algodão e amendoim vs o consórcio $(\mathrm{P} \leq 0,01)$, conforme análise de variância.

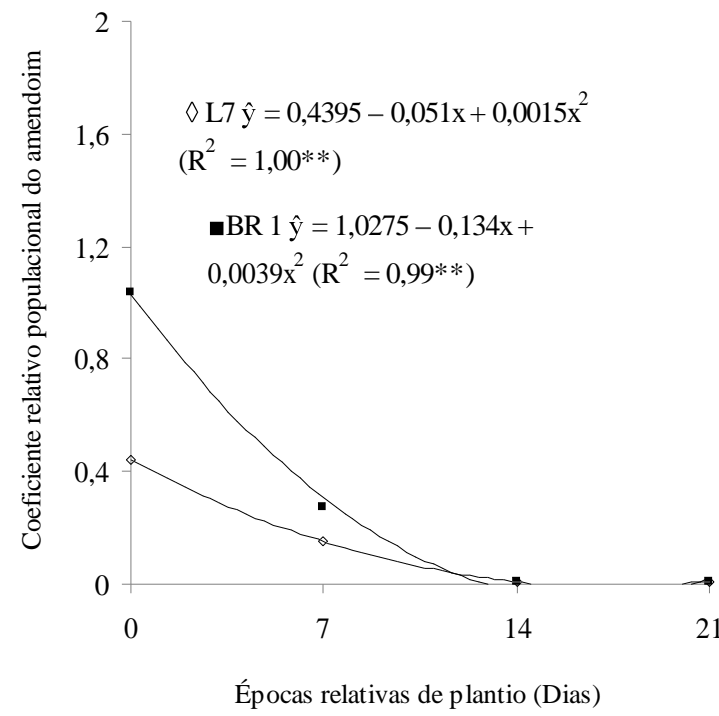

Figura 3 - Regressão do coeficiente relativo populacional em função das épocas relativas de semeadura.. Épocas relativas de semeadura/amendoim. 
Tabela 3 - Desdobramento da interação significativa entre os fatores cultivares de algodão e cultivares de amendoim, em sistema de consórcio para as variáveis renda bruta e taxa de retorno.

\begin{tabular}{|c|c|c|c|c|}
\hline \multirow[t]{3}{*}{$\begin{array}{c}\text { Cultivares de } \\
\text { algodão }\end{array}$} & $\begin{array}{c}\text { Renda Bruta } \\
(\mathrm{R} \$)\end{array}$ & \multicolumn{3}{|c|}{$\begin{array}{l}\text { Taxa de } \\
\text { Retorno }\end{array}$} \\
\hline & \multicolumn{4}{|c|}{ Cultivares de amendoim } \\
\hline & L7 & $\mathrm{BR}-1$ & L7 & $\mathrm{BR}-1$ \\
\hline BRS 186 & $2671,73 \mathrm{bA}$ & $3057,08 \mathrm{aA}$ & $2,97 \mathrm{bA}$ & $3,38 \mathrm{aA}$ \\
\hline Brs 201 & $3614,46 \mathrm{aA}$ & $3110,75 \mathrm{aA}$ & $3,96 \mathrm{aA}$ & $3,45 \mathrm{aA}$ \\
\hline
\end{tabular}

Médias assinaladas pela mesma letra maiúscula nas linhas e por mesma letra minúscula nas colunas não diferem entre si pelo teste de Tukey, a 5\% de probabilidade.

Tabela 4 - Comparação entre as médias dos monocultivos de algodão e amendoim e o sistema consorciado, em função das variáveis renda bruta, renda líquida e taxa de retorno.

\begin{tabular}{lccc}
\hline Sistemas de cultivo & Renda bruta (R $\$)$ & Renda líquida $(\mathrm{R} \$)$ & Taxa de retorno \\
\hline BRS 186 & & & \\
Monocultivo & $5056,00 \mathrm{a}$ & $4156,00 \mathrm{a}$ & $5,62 \mathrm{a}$ \\
Consórcio & $3113,51 \mathrm{~b}$ & $2213,49 \mathrm{~b}$ & $3,44 \mathrm{~b}$ \\
\hline BRS 201 & & & \\
Monocultivo & $5390,50 \mathrm{a}$ & $4490,50 \mathrm{a}$ & $6,01 \mathrm{a}$ \\
Consórcio & $3113,51 \mathrm{~b}$ & $2213,49 \mathrm{~b}$ & $3,44 \mathrm{~b}$ \\
\hline L7 & & & \\
Monocultivo & $596,10 \mathrm{~b}$ & $-303,82 \mathrm{~b}$ & $0,66 \mathrm{~b}$ \\
Consórcio & $3113,51 \mathrm{a}$ & $2213,49 \mathrm{a}$ & $3,44 \mathrm{a}$ \\
\hline BR1 & & $-69,01 \mathrm{~b}$ & $0,92 \mathrm{~b}$ \\
Monocultivo & $830,99 \mathrm{~b}$ & $2213,49 \mathrm{a}$ & $3,44 \mathrm{a}$ \\
Consórcio & $3113,51 \mathrm{a}$ & $\mathrm{a} \mathrm{p}$ & $\mathrm{C}$
\end{tabular}

Médias assinaladas pela mesma letra nas colunas e para cada fator não diferem entre si pelo teste de Tukey, a $5 \%$ de probabilidade.

O algodoeiro BRS 201 foi o que proporcionou maior valor, tanto em consórcio quanto em cultivo isolado com redução significativa dos valores referentes a essa variável quando as duas cultivares foram consorciadas com o amendoim (Tabela 4). Para o algodoeiro BRS 201, a redução foi de 46,74\% enquanto que, para o algodoeiro BRS 286 Precoce 3, a redução foi de 50,70\%. Os resultados encontrados para o consórcio algodoeiro herbáceo e amendoim foram insatisfatórios já que a renda líquida da leguminosa, mesmo solteira, foi negativa. Portanto, o cultivo do amendoim não compensou a redução da renda líquida proporcionada pelo algodoeiro, por conta do consórcio.

Quanto à variável taxa de retorno foi verificado efeito significativo, apenas para o fator cultivares de algodão $(\mathrm{P} \leq 0,01)$, para a interação entre os fatores cultivares de algodão e cultivares de amendoim $(\mathrm{P} \leq 0,05)$ (Tabela 3$)$ e para os contrastes entre os monocultivos duas cultivares de algodão e amendoim vs o consórcio $(\mathrm{P} \leq 0,01)$, conforme análise de variância (Tabela 4).

Julgando-se apenas esse índice considera-se mais eficiente o sistema algodão BRS 201 isolado, com valor de 6,01. A mesma cultivar de algodão, consorciada ao amendoim L7 possibilitou uma taxa de retorno de 3,96, maior valor encontrado para o cultivo consorciado. Verificou-se, portanto, redução significativa dos valores referentes a essa variável quando optou-se pelo consórcio entre a malvácea e a leguminosa (Tabela 4). Tal fato ocorreu, principalmente, em função das baixas produtividades do amendoim, já que esse índice refere-se à relação entre a renda bruta e o custo total da produção.

Beltrão et al. (2001a) encontraram para o consórcio algodão herbáceo 186 Precoce 3 + gergelim uma taxa de retorno média de 2,17. Beltrão et al. (1986b), trabalhando com algodão herbáceo CNPA - $2 \mathrm{H}$, consorciado com sorgo, observou que apenas um tratamento consorciado 
apresentou taxa de retorno maior do que a testemunha. Já no consórcio da mesma cultivar de algodão herbáceo com feijão caupi Beltrão et al. (1986a) encontraram taxas de retorno sempre maiores, em relação ao monocultivo de algodão.

\section{CONCLUSÕES}

O algodão foi mais competitivo nas duas últimas épocas relativas de semeadura, quando o amendoim foi semeado 14 e 21 dias após o algodão.

De acordo com o índice de uso eficiente da terra, a área foi melhor aproveitada quando o amendoim foi semeado ao mesmo tempo que o algodão, pois seus valores estiveram abaixo de 1,0 nas três últimas épocas de semeadura, sendo a malvácea muito mais competitiva.

Considerando-se os indicadores econômicos renda bruta, renda líquida e taxa de retorno não houve, no caso em tela, vantagem econômica para quando o algodão foi plantado em consórcio com o amendoim, já que os valores referentes ao consórcio foram menores do que os cultivos isolados.

\section{REFERÊNCIAS BIBLIOGRÁFICAS}

BELTRÃO, N. E. de M.; NÓBREGA, L. B. da; AZEVEDO, D. M. P. de; VIEIRA, D. J. Comparação entre indicadores agroeconômicos de avaliação de agroecossistemas consorciados e solteiros envolvendo algodão "ÜPLAND" e feijão “CAUPI”. Campina Grande: Embrapa-CNPA, 1984 $36 \mathrm{p}$.

BELTRÃO, N. E. de M.; NÓBREGA, L. B. da; AZEVÊDO, D. M. P. de; VIEIRA, D. J.; CRISÓSTOMO, J. R. Algodoeiro herbáceo em consórcio com cultivares de caupi. Pesquisa Agropecuária Brasileira, Brasília, v. 21, n. 3, p. 271-284, mar. 1986a.

BELTRÃO, N. E. de M.; PEREIRA, J. R.; OLIVEIRA, J. N. de. Consorciação algodoeiro herbáceo e gergelim: efeitos dos fatores cultivares, configurações de plantio e épocas relativas de plantio III: indicadores econômicos. In: CONGRESSO BRASILEIRO DE ALGODÃO, 3., 2001, Mato
Grosso do Sul. Anais... Campina Grande: Embrapa-CNPA, 2001a. p. 615-617.

BELTRÃO, N. E. de M.; PEREIRA, J. R.; OLIVEIRA, J. N. de. Consorciação algodoeiro herbáceo e gergelim: efeitos dos fatores cultivares, configurações de plantio e épocas relativas de plantio IV: indicadores de competição. In: CONGRESSO BRASILEIRO DE ALGODÃO, 3., 2001, Mato Grosso do Sul. Anais... Campina Grande: Embrapa-CNPA, 2001b. p. 622-624.

BELTRÃO, N. E. de M.; VIEIRA, D. J.; AZEVÊDO, D. M. P. de; NÓBREGA, L. B. da. Importância da configuração de plantio e da cultivar de sorgo em consórcio com o algodoeiro herbáceo. Pesquisa Agropecuária Brasileira, Brasília, v. 21, n. 2, p. 173-185, fev. 1986b.

EMPRESA BRASILEIRA DE PESQUISA AGROPECUÁRIA. Sistema brasileiro de classificação de solos. Rio de Janeiro, 1999. 412 p.

GOMES, F. P. Curso de estatística experimental. 11. ed. Piracicaba: Nobel, 1985. 466 p.

MENDES, H. C. Cultura e adubação do algodoeiro. São Paulo: Instituto Brasileiro de Potassa, 1965. 471 p.

PORTES, T. de A. Produção de feijão nos sistemas consorciados. Goiânia: Embrapa-CNPAF, 1996. 50 p.

SILVA, M. B. da; BELTRÃO, N. E. de M. Níveis populacionais e configurações de plantio na cultura do amendoim, em regime de sequeiro na mesorregião do agreste da Borborema do Estado da Paraíba. Revista de Oleaginosas e Fibrosas, Campina Grande, v. 4, n. 1, p. 2334, 1998.

TRENBATH, B. R. Plant Interactions in mixed crop comunities. In: PAPENDICK, R. I. et al. Multiple cropping. Madison: American Society of Agronomy, 1979. p. 129-69. 